\title{
Preventing School Shootings: The Interprofessional and Community Approach to Prevention
}

\author{
Heather C. Alonge, $\mathrm{PhD}$ \\ Walden University, Minneapolis, Minnesota, United States \\ (iD https://orcid.org/0000-0001-6418-4150 \\ Constant P. Craig, MSM \\ Colorado Technical University, Colorado Springs, Colorado, United States \\ (iD) https://orcid.org/0000-0003-4909-2383
}

Contact: heather.alonge@mail.waldenu.edu or ccraig@coloradotech.edu

\begin{abstract}
This essay examined the issue of school shootings within the United States, to include a literature review and analysis of the current status of the issue on a national level. From the review and analysis, the essay provides the multidisciplines engaged in school safety issues with viable, workable, and quickly implementable solutions to address this serious national issue at the local school district and even school level of implementation. This analysis examined a multidiscipline and multiprofessional community approach using existing federal guidelines that address actionable intelligence (social media and human information/informants), school design and incorporation of safety and protective features, involvement of law enforcement on campuses, and engagement of law enforcement with administrators and educators. Most importantly, it provides awareness to educators, administrators, and law enforcement along with the general public that the attitude of "It can't happen here" can indeed and way too many times it has "happened here."
\end{abstract}

Keywords: school shootings; active shooter prevention; interprofessional approach; trifecta of prevention

Date Submitted: February 3, 2020 | Date Published: April 8, 2020

\section{Recommended Citation}

Alonge, H. C., \& Craig, C. P. (2020). Preventing school shootings: The interprofessional and community approach to prevention. Journal of Social Change, 12, 32-39. https://doi.org/10.5590/JOSC.2020.12.1.04

\section{Introduction}

There is national interest on the topic of school shootings by numerous groups and stakeholders. First, parents and voters with school-age children are concerned and engaged, knowing that any solution or solutions will involve money through more taxes. Second, as the first line of defense and responders, practitioners of homeland security, emergency management, and law enforcement have professional views and interests toward preparation (including planning and mitigation), response, and recovery but also detection and prevention. Third, the academic community brings research, analysis, and teaching of the homeland security/emergency management and law enforcement professions at the undergraduate and 
graduate levels to national debate and discussion. Fourth, the administrators and faculty at individual schools and school districts have an immediate and intimate concern and stake in any actions designed to detect, deter, disrupt, or prevent school shootings. The fifth group of stakeholders includes students. Students are often much more aware of issues and activities within the school, on school property, and social media and social interactions than any of the preceding groups (Devos et al., 2018; Pollack et al., 2008). However, while the debate goes on in the media, many are concerned whether there are meaningful additions to the body of knowledge. Discussion is also being driven by the second amendment debate, which was apparent in several political races in the primary season of 2018 but has now faded into the background for the 2020 election cycle.

Given the number of school shootings that occurred from the Columbine High School shooting on April 20, 1999, through the Marjory Stoneman Douglas High School (MSDHS) shooting on February 14, 2018, this is an ongoing and national issue without current resolution. The Federal Commission on School Safety researched the issue and submitted a final report with limited actionable recommendations at the federal, state, and local levels (Devos et al., 2018) to the president of the United States. The U.S. Department of Homeland Security (DHS, 2020) has elevated the issue by placing school safety on its home page website. This article presents the possibility of an interprofessional approach that includes school district administrators and parents, students, and community members to address school shooting prevention.

\section{Literature Review}

Much has been written on school shootings, but most of the literature falls into specific categories. The available literature is generally on training or training related regarding active shooter training, vulnerability assessments of school and school buildings with associated checklists, official after action reports from school shootings, media reports of school shootings, and numerous personal opinion or academic research pieces on the topic of the shooter's mental state. Sources include news media outlets; official U.S., state, and local government documents; commercial enterprises like for profit and not-for-profit businesses; and internetbased blogs and other social- and professional-based media. Psychologists have offered ideas and explanations to address the problem as well.

\section{Analysis of Attacks}

The Final Report and Findings of the Safe School Initiative: Implications for the Prevention of School Attacks in the United States (Vossekuil et al., 2004) provided 10 key findings that provide insight on school shootings:

1. Incidents of targeted violence at school rarely were sudden, impulsive acts.

2. Prior to most incidents, other people knew about the attacker's idea and/or plan to attack.

3. Most attackers did not threaten their targets directly prior to advancing the attack.

4. There is no accurate or useful "profile" of students who engaged in targeted school violence.

5. Most attackers engaged in some behavior prior to the incident that caused others concern or indicated a need for help.

6. Most attackers had difficulty coping with significant losses or personal failures. Moreover, many had considered or attempted suicide.

7. Many attackers felt bullied, persecuted, or injured by others prior to the attack.

8. Most attackers had access to and had used weapons prior to the attack.

9. In many cases, other students were involved in some capacity. 
10. Despite prompt law enforcement responses, most shooting incidents were stopped by means other than law enforcement intervention. (pp. 3-4)

Although The Final Report and Findings of the Safe School Initiative: Implications for the Prevention of School Attacks in the United States is over a decade old, attacks since the original publication are consistent with these observations as well as these additional insights based upon the Final Report of the Federal Commission on School Safety (Devos et al., 2018):

1. In almost three quarters of the incidents, the attacker killed one or more students, faculty, or others at the school.

2. More than one half of the attacks occurred during the school day.

3. All the incidents of targeted school violence examined in the Safe School Initiative were committed by boys or young men.

4. In most of the incidents, the attackers carried out the attack alone.

5. Most attackers used some type of gun as their primary weapon.

6. In over half of the incidents the attacker had selected at least one school administrator, faculty member, or staff member as a target.

7. In nearly half of the incidents, the attackers were known to have chosen more than one target prior to their attack.

8. Most attackers had a grievance against at least one of their targets prior to the attack.

9. Individuals who were targeted prior to the attack also became victims (i.e., individuals harmed in the attack). It was noted that none-targeted individuals were often injured or killed as well. These individuals were students, faculty, or staff. (Vossekuil et al., 2004, p. 4)

Numbers 3 and 4 from this list have statistics that are consistent with current statistics. Further, assailant and victimology information were significant to this report and appear to be consistent with current attacks.

\section{Threat/Hazard Analysis Methods}

The U.S. Centers for Disease Control and Prevention (2019) has identified school violence as an issue and includes shootings as an element, issuing a fact sheet to address the matter. The Centers for Disease Control and Prevention viewed the matter as being health (including mental health) related and has developed several tools to enable schools and school districts to conduct surveys and analysis. The Department of Education in cooperation with the U.S. Secret Service (a DHS operating agency) has also created a guide to assist schools and school districts in assessing threats. This guide was derived from the data and information developed in the Safe School Initiative highlighted in the previous section (Vossekuil et al., 2014).

The Secret Service's National Threat Assessment Center has further reinforced and updated these guidelines to reflect current thoughts on potential threats. Key concepts include (a) development and use of multidisciplinary threat assessment teams, (b) definition of threatening and prohibited behaviors, (c) creation of a central reporting mechanism, (d) determination of the threshold for law enforcement involvement, (e) establishment of assessment procedures, ( $\mathrm{f}$ ) development of risk management options, ( $\mathrm{g}$ ) creation and promotion of safe school environments, and (h) training for all stakeholders as presented in Enhancing School Safety Using a Threat Assessment Model: An Operational Guide for Preventing Targeted School Violence (National Threat Assessment Center, 2018, p. 3).

\section{Observations}

The reviewed reports and studies are consistent across time in terms of identifying the threat and general conditions of the events. But the primary unknown factor is the actual detection of the threat in the form of 
the shooter and the shooter's intentions. In all reviewed cases, the shooter or shooters had communicated the intention of committing these acts, which has been increasingly done via social media among other forms of communication. However, there are still no clear solutions to help prevent school shootings. Though a risk formula can be expressed as $\mathrm{R}=\mathrm{T} \times \mathrm{V} \times \mathrm{C}$, where $\mathrm{R}=$ risk, $\mathrm{T}=$ threat, $\mathrm{V}=$ vulnerability, and $\mathrm{C}=$ consequences (Masse et al., 2017), risk is difficult to determine because the threat is often undefined or difficult to detect (Vossekuil et al., 2004). Potential solutions are offered by a variety of sources, but the most effective methods are offered by the Safe Schools Initiative (National Threat Assessment Center, 2019).

Additionally, although schools in inner city areas have addressed potential school shootings under an assumption that violence will occur by taking steps to ensure that weapons do not enter the school campus, there are still vulnerabilities such as open school gates, multiple access points, and distracted school resource officers (MSDHS Public Safety Commission, 2019b, pp. 10-16) A false sense of security develops when school districts have school resource officers and conduct active shooter training for resource officers, local law enforcement agencies, school staff and faculty, and in many cases students. These steps may deter attacks, but they do not help detect, disrupt, or prevent an attack. Based on the review of the literature, threat analysis is a part of the equation that has been ignored.

\section{Confusion of Lead Agencies and Jurisdictions}

Based on the volume and source of literature, local school districts and law enforcement agencies may be confused about federal agency involvement and jurisdiction with the issue of school shootings, which was confirmed in a recent media release concerning the formation of the Federal Commission on School Safety (U.S. Department of Education, 2018). The Department of Education has been directed to lead this multiagency commission and effort, which includes the secretaries of the Departments of Justice, Homeland Security, and Health and Human Services along with the Department of Education.

\section{"It Can't Happen Here" Syndrome}

Recent school shootings have been in upscale communities, but the public sentiment that "it can't happen here" is expressed by citizens, parents, school officials and even law enforcement (as indicated on p. 13 of the MSDHS Public Safety Commision, 2019a, shooting report). As the chairman of the MSDHS Public Safety Commision (2019b) wrote, "Complacency is driven, at least in part, by the erroneous notion that a school shooting will not 'happen here' and that these events happen 'somewhere else"” (p. 2. This mentality was present in Parkland prior to the MSDHS shooting, as there had been no active assailant drill on the MSDHS campus during the year preceding the shooting, and school gates and doors were left unlocked, open, and unattended, an issue also addressed in prior reports and analysis (Vossekuil et al., 2004). Another example is Broward County Public Schools, which had no written active shooter policy (MSDHS Public Safety Commission, 2019a, 2019b).

\section{The Trifecta of Prevention}

The current embedding of schools as a "government facilities critical infrastructure asset" (National Security Staff, 2013) has not been enough to protect children in schools, which has led to the formation of the Federal Commission on School Safety. Local schools and school districts and often states are taking a proactive position in developing security for schools, providing training to respond to school shootings, and even taking steps to detect school shooters. However, these steps may be faced with funding, manpower, and jurisdictional issues that are politically charged or cannot be implemented in a timely, efficient manner (National Threat Assessment Center, 2018). Thus, timely and appropriate responses by the decision makers of the president's Commission on School Safety are necessary to resolve the ongoing issue of school shooters. 
Furthermore, it is important to recognize that it takes an interprofessional collaboration among educators, law enforcement, and public health practitioners in order to prevent school shootings.

Existing operating models and legal precedence provide effective methods of addressing potential resolution within a short and reasonable time frame that can have a positive impact toward preventing future school shootings. The legal basis for implementation of the recommendations exists within the Patriot Act of 2001 and the Homeland Security Act of 2002. The key and primary assumption under this solution is that current, future, and potential school shooters are domestic terrorists with similar goals and objectives as other individual or group of domestic terrorists. For example, recent events in New Mexico suggest that school shootings are a terrorist opportunity (Lee \& Hudetz, 2018). Although the individual school shooter's goals or objectives may not be as apparent, these goals and objectives in most cases have been stated to others in one form or another (Pollack et al., 2008).

\section{Recognition of School Shooters as Domestic Terrorists Rationale}

School shooters are domestic terrorists in nature. The intent of a school shooter is to cause death and destruction and gain as much personal "fame" or infamy as possible. Like terrorists, the planning is hidden but the presence of anger (DHS, 2018) against specific individuals or groups of individuals is generally public (Pollack et al., 2008). Elevating the school shooters to domestic terrorist status would allow federal law enforcement jurisdiction for investigative and prosecution purposes and provide a nationwide standard of investigation. Although the crime would be a federal crime, the involvement of state, local, tribal, and territorial (SLTT) law enforcement and education officials is essential to the detection, prevention, response, recovery, law enforcement investigation, and prosecution (if applicable) of these individuals. In the case of the MSDHS shooting, the Federal Bureau of Investigation was aware of the threat from this specific individual but did not act accordingly to inform state or local law enforcement and school officials (Berman \& Zapotosky, 2018).

\section{Interprofessional and Community Efforts for Prevention}

Current U.S. law addressing domestic terrorism is in force and enforceable under the Patriot Act of 2001, the Homeland Security Act of 2002, and the Intelligence Reform and Terrorism Prevention Act of 2004. However, a realignment of national policy is necessary to address the issue of school shootings. A homeland security presidential directive to recognize potential school shooters as domestic terrorists would provide policy guidance for the executive branch. The Federal Commission on School Safety can provide the National Security Staff and the Homeland Security Committee with a draft recommendation for this homeland security presidential directive. This policy realignment would be the basis for adjustments to the National Homeland Security Strategy, the National Response Framework, the National Incident Management System, the Critical Infrastructure Protection Plan, and the sector specific Government Facilities Protection Plan and other doctrinal publications at the federal government level.

Currently schools at all levels are lumped into the government facilities sector of critical infrastructure protection as managed by the newly created Cybersecurity and Infrastructure Security Agency, of the DHS. However, there is an inherent difference in the potential threat situation to all other critical infrastructure and schools. Although all government buildings are potential domestic and/or international terrorist targets, schools are different in that the threat is often an insider threat. The insider threat is difficult to detect, deter, and disrupt, and it is difficult to respond due to unique insider knowledge (Pollack et al., 2008).

Based on these concerns for addressing school shootings, the Presidential Policy Directive 21 and Executive Order 13636 of February 13, 2013, should be adjusted to add schools as a new critical infrastructure sector 
(this would be the 17th sector). In adding this new or elevated sector, the sector specific agency would be coidentified as both the Cybersecurity and Infrastructure Security Agency of the DHS and the Department of Education. The latter would create a new "office" within its organization to specifically deal with schools and school security issues for the Department of Education. This action would define and clarify jurisdiction, authority, and responsibilities at the federal level and this action would be usable at SLTT levels of government as well to help resolve confusion of jurisdiction and authority issues.

\section{Creation of Social Media Intelligence}

As part of changing policy to address school shootings, fusion centers would play a part in helping prevent attacks (DHS, 2018). According to DHS (2018), fusion centers are state and local areas for the receipt, analysis, gathering, and sharing of threat-related information among SLTT partners such as frontline law enforcement, public safety, fire service, emergency response, public health, critical infrastructure protection, and private sector security personnel. They also inform government decisions by providing interdisciplinary expertise and situational awareness. Furthermore, by facilitating information sharing, law enforcement and homeland security partners can prevent, protect against, and respond to crime and terrorism (DHS, 2018).

\section{The Community}

Any definition of Community must involve school administrators, school faculty, school district administrators, students, and parents as part of the total community. Students and parents are the most critical part of the detection and therefore prevention in any discussion involving school safety (National Threat Assessment Center, 2018; Pollack et al., 2008). The community must be part of the information and intelligence model. The State of Florida has recently enacted a series of state statutes designed to enhance this form of "actionable intelligence" in a manner of helping to find useful information (MSDHS Public Safety Commission, 2019b).

\section{Conclusion}

The "not our school" syndrome has been identified as a contributing factor to a school shooting occurring by not being detected in time to deter, disrupt, or prevent (MSDHS Public Safety Commission, 2019a, 2019b). As noted in the most recent Safe Schools Initiative Report by the Department of Education and the U.S. Secret Service, addressing this issue must involve students, faculty, staff, and school resources officers (law enforcement) in an environment of mutual trust and information exchange to ensure early detection that enables prevention (National Threat Assessment Center, 2019). This is good for a local level start; however, this issue goes beyond the capabilities of most SLTT governments to address. But a unified effort between the Departments of Education, Homeland Security, and Justice can establish an enterprise (as a distinct part of the Homeland Security Enterprise) to combat this public threat. However, every recommendation must clearly and fully involve students and their parents, faculty, school administrators at school and district levels, law enforcement, and health care professionals at the local, state and federal levels. This is a significant social change and implements the concepts of the DHS's (2020) "See something, say something" to a significantly broader application that includes the physical of the school campus, the students' social settings, and the emergence of social media. This has initial planning and support from the U.S. Department of Education that is specifically directed at educators and support staff in the form of the SchoolSafety.gov (n.d.) website. 


\section{References}

Berman, M., \& Zapotosky, M. (2018, February 16). The FBI said it failed to act on a tip about the suspected Florida school shooter's potential for violence. The Washington Post.

https://www.washingtonpost.com/news/post-nation/wp/2018/02/16/as-florida-town-mournsauthorities-revisit-possible-warning-signs-before-schoolmassacre/?noredirect $=$ on\&utm term $=.1$ adeded $8 \mathrm{bdb2}$

Centers for Disease Control and Prevention. (2016). Understanding school violence [Fact sheet]. Department of Health and Human Services.

Devos, B., Nielsen, K., Azar, A., \& Whitaker, M. (2018). Final report of the Federal Commission on School Safety. Government Printing Office.

Homeland Security Act of 2002, H.R. 5005, P.L. 107-296 (2002).

Lee, M., \& Hudetz, M. (2018, August 8). Kids at New Mexico compound near Colorado border were trained to commit school shootings, prosecutor says. The Denver Post. https://www.denverpost.com/2018/08/08/new-mexico-child-compound/

Marjory Stoneman Douglas High School (MSDHS) Public Safety Commision. (2019a, January 2). Marjory Stoneman Douglas High School Public Safety Commision Initial Report Submitted to the Governor, Speaker of the House of Representatives and Senate President. http://www.fdle.state.fl.us/msdhs/commissionreport.pdf

Marjory Stoneman Douglas High School (MSDHS) Public Safety Commission. (2019b, November 1). Marjory Stoneman Douglas High School Public Safety Commission Report Submitted to the Governor, Speaker of the House of Representatives and Senate President. http://www.fdle.state.fl.us/MSDHS/MSD-Report-2-Public-Version.pdf

Masse, T., O’Neil, S., \& Rollins, J. (2007). The Department of Homeland Security's risk assessment methodology: Evolution, issues, and options for Congress. Congressional Research Service. https://fas.org/sgp/crs/homesec/RL33858.pdf

National Security Staff. (2013). Presidential Policy Directive 21 critical infrastructure security and resilience. https://obamawhitehouse.archives.gov/the-press-office/2013/02/12/presidential-policy-directivecritical-infrastructure-security-and-resil

National Threat Assessment Center. (2018). Enhancing school safety using a threat assessment model: An operational guide for preventing targeted school violence. https://www.cisa.gov/sites/default/files/publications/18 0711 USSS NTAC-Enhancing-SchoolSafety-Guide.pdf

Pollack, W. S., Modzeleski, W., \& Rooney, G. (2008). Prior knowledge of potential school-based violence: Information students learn may prevent a targeted attack: U.S. Secret Service and the U.S. Department of Education. https://rems.ed.gov/docs/DOE_BystanderStudy.pdf

SchoolSafety.gov. (n.d.). Find resources to create a safer school. https://www.schoolsafety.gov/?utm source=hp slideshow\&utm medium=web\&utm campaign=dhsgov

U.S. Department of Education. (2018, March 20). Federal Commission on School Safety [Press release]. https://www.ed.gov/school-safety

U.S. Department of Homeland Security (DHS). (2018, January 2). National Network of Fusion Centers [Fact sheet]. https://www.dhs.gov/national-network-fusion-centers-fact-sheet 
U.S. Department of Homeland Security (DHS). (2020, January 1). If you see something, say something. https://www.dhs.gov/see-something-say-something

Vossekuil, B., Fein, R. A., Reddy, M., Borum, R., \& Modzeleski, W. (2004). The final report and findings of the safe school initiative: Implications for the prevention of school attacks in the United States. https://www2.ed.gov/admins/lead/safety/preventingattacksreport.pdf 